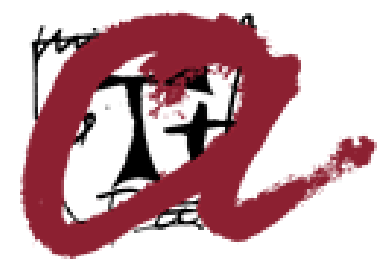

UNIVERSITAT ROVIRA I VIRGILI

DEPARTAMENT D'ECONOMIA

\title{
WORKING PAPERS
}

\section{Col-lecció "DOCUMENTS DE TREBALL DEL DEPARTAMENT D'ECONOMIA - CREIP”}

Seasonality of hotel demand in the main Spanish provinces: measurements and decomposition exercises

Juan Antonio Duro

Document de treball n.21- 2015

\section{DEPARTAMENT D'ECONOMIA - CREIP}

Facultat d'Economia i Empresa 

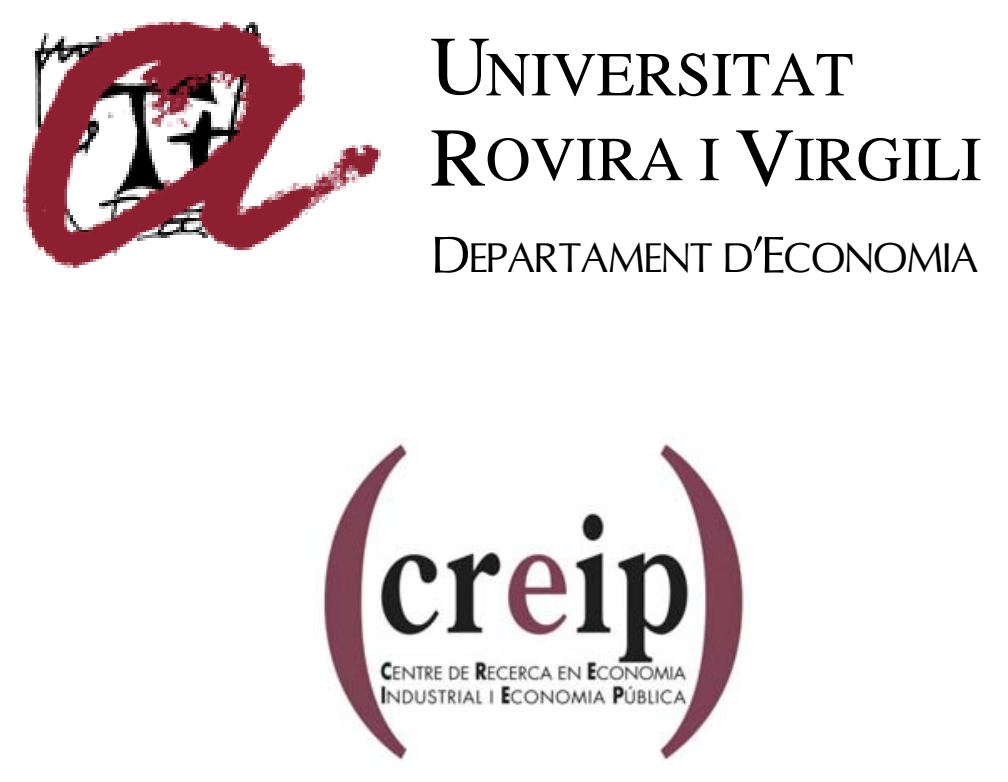

Edita:

Departament d'Economia

www.fcee.urv.es/departaments/economia/publi c_html/index.html

Universitat Rovira i Virgili

Facultat d'Economia i Empresa

Avgda. de la Universitat, 1

43204 Reus

Tel.: +34 977759811

Fax: +34 977300661

Email: sde@urv.cat

\section{CREIP}

www.urv.cat/creip

Universitat Rovira i Virgili

Departament d'Economia

Avgda. de la Universitat, 1

43204 Reus

Tel.: +34 977558936

Email: creip@urv.cat

Adreçar comentaris al Departament d'Economia / CREIP

Dipòsit Legal: T - 1032 - 2015

ISSN edició en paper: 1576 - 3382

ISSN edició electrònica: 1988 - 0820 


\title{
Seasonality of hotel demand in the main Spanish provinces: measurements and decomposition exercises
}

\section{Juan Antonio Duro}

Department of Economics and CREIP, Universitat Rovira i Virgili, Av. de la Universitat, 1, 43204 Reus, Spain. Tel: 0034977759816. Fax: 0034

977300661. Email: juanantonio.duro@urv.net.

\begin{abstract}
This paper analyses the seasonal concentration of tourist activity in the main Spanish provinces for the period 1999-2012, taking hotel nights as the indicator of reference. We propose using several standard summary measures in order to evaluate the level, evolution and some decompositions. Our main results can be summarized as follows: first, across the whole country and especially since 2007 , there is a growth in seasonality; second, seasonal concentration is greatest in the Balearic Islands and two of the Catalan provinces, and least in Madrid and the Canary Island provinces; third, although the overall patterns typically agree, nevertheless, in some provinces the indexes we deal with show some discrepancies; fourth, the decomposition of the monthly concentration by major markets typically indicates the main role played by the foreign component; finally, the overall evidence does not support the thesis that the domestic market offsets the foreign one.
\end{abstract}

Keywords: seasonality; concentration indices; decomposition analysis; Spanish provinces

\footnotetext{
${ }^{*}$ The author acknowledges support from project ECO2013-45380-P.
} 


\section{Introduction}

Baron (1975) highlights seasonality, or rather the seasonal concentration of tourist activity, as one of the main problems facing mature tourist destinations. Consequently, it is predictable that most of their medium- and long-term development and consolidation strategies would include a significant reduction in seasonality as one of their main policy goals, or, to put it another way, a greater balance in the distribution of tourist flows throughout the year. The reasons for this concern are well known (Baum, 1999). Firstly, there are concerns about its impact on social and environmental sustainability (Manning and Powers, 1984). The environmental effects include the effects on wildlife, erosion, noise and environmental pollution, both directly and indirectly through the consumption of inputs that have significant impacts. The social effects have to do with the effects of this concentration on the welfare of the residents these arise from traffic problems, security, parking, queues, etc. In fact, these impacts affect the welfare, not only of the residents, but also of the tourists themselves Secondly, there is concern about the repercussions in terms of economic inefficiency and the deficient use of both public and private resources (Roselló et al., 2004). Indeed, seasonality gives rise to resource-use saturation at some times of the year, with consequent effects on satisfaction levels and service quality while, at other times, resources are under-used, with consequent problems associated with revenues and private profitability. Finally, there are worrying implications in terms of the labour market, salaries and disincentives for investment in human capital (Krakover, 2000). So, seasonality creates difficulties in recruiting and retaining workforce, can disincentive investment in human capital and, finally, will result in reduced labour qualification and/or over qualification.

For all these reasons it is logical that the academic literature has devoted attention to studying seasonality from various different approaches. In this respect, Koenig-Lewis and Bischoff (2005), in their well-known survey, identified 
the six main topics of interest in relation to the analysis of seasonality, with significant shortfalls in each of them. These were: the definitions of seasonality; its causes and its impacts; the policy implications; studies into consumer behaviour and approaches to measuring seasonality. This paper focuses fundamentally on the last of these aspects.

To deal with the question of measuring this phenomenon consistently, it first needs to be clarified what exactly is understood by seasonality. In this respect, the literature uses slightly different connotations, although in most cases they refer to seasonality as the emergence in a given destination of a systematic pattern of tourist flows during the year (Baron, 1975; Allock, 1994; Butler 2004, among others). On this regard, the definition that it seems most acceptable in general terms is the one established by Butler (1994), who describes it as "a temporal imbalance in the phenomenon of tourism which can be expressed in terms of different indicators". Based on this last definition, therefore, seasonality would essentially be a distributional imbalance, which can be measured synthetically.

Taking the above definition as a reference, it would therefore be necessary to take synthetic distribution indices and apply them to the annual distribution of tourist activity. Surprisingly, few papers in the literature focus on this type of measurement of seasonality (Wanhill, 1980; Lundtorp, 2001; FernándezMorales, 2003; Fernández-Morales and Mayorga-Toledano, 2008 or Martín et al., 2014). In particular, the literature on the measurement of inequality specifically indicates a set of satisfactory synthetic measures like Gini coefficient (widely used in seasonality applications until now), Theil indexes or the Coefficient of Variation (CV hereafter) (Cowell, 1995). The problem, however, is that there is no single measurement preferable than the rest. This is mainly because each of them has a different weighting on the changes in the different months (i.e. basic analysis units) (Duro, 2012). In this case, the researcher either needs to explain his or her evaluation in this respect or otherwise deal with a broad set of indicators to obtain a comprehensive overview of the situation. So far, the literature on measurement of seasonality does not seem to have devoted much attention to this. 
In addition to the global measurement, an important analytical aspect to be taken into account is the decomposition possibilities of the indexes. In this respect, the literature on inequality measurement (Cowell, 1995) essentially emphasizes the usefulness of two possibilities: firstly, the indices, or some of them, may be decomposed by groups, identifying an inter-group component and other intra-group ones (Shorrocks, 1984). In the seasonality case, the groups would be formed by consecutive months or, to put in another way, tourism seasons. This analysis, for example, is interested in terms of the reliability of monthly aggregates as an instrument for explaining global concentrations and as a tool for public planning; secondly, the literature has highlighted the interest in using decompositions when the factors can be expressed additively (also a common example in indicators of tourist demand) (Shorrocks, 1980 and 1982). In this sense, it would be necessary to address the role of each factor (source markets for instance) in measuring annual seasonality. Regarding inequality decomposition analyses in the international context we are only aware of the studies by Fernández-Morales (2003) and Fernández-Morales and Mayorga-Toledano (2008). The former made an analysis of the monthly concentration of hotel nights in three southern Spanish provinces (Almeria, Granada and Malaga), using the Gini coefficient and its decomposition by groups (i.e. seasons) as a sole indicator. In the latter study, the authors decomposed by source (e.g. markets) the concentration of tourist activity, this being measured analogically using again the Gini coefficient, for the provinces in the south of Spain.

Consequently, this paper aims firstly to highlight the importance of methodological elements of interest in relation to the measurement and decomposition of seasonality, one of the main research lines suggested by Koenig-Lewis and Bischoff (2005) but little investigated in the literature. In particular, in the first case, and given the differential characteristics of the measures, this paper proposes the joint use of the Gini coefficient (the index typically used in the seasonality applications), the Theil Index and CV in order to provide a sufficiently broad qualitative range and avoid over-extending the number of measures. In this way, it hopes to overcome the academic literature's obsession with the Gini coefficient. Meanwhile, the paper also reviews the main 
methodological elements relating to the implementation of decomposition exercises, highlighting, for example, the advantages of the Theil Index over the Gini coefficient in some cases. This being the case, it examines the possibilities associated with the use of decomposition by groups (by monthly periods) and by sources (markets). Indeed, both these methodological elements stem from extending the instruments currently available in the field of inequality measurements, which, up to now, have received little attention in the academic literature on tourism. Secondly, the paper makes an analysis of tourist seasonality based on the above mentioned instrumental methodology for the main Spanish provinces, which make up 83\% of the total demand in Spain, thus providing quite comprehensive territorial coverage. The analysis is conducted using hotel nights as an indicator, based on the figures extracted from the Hotel Occupancy Survey conducted monthly by the Spanish National Institute and for the longest period available, i.e. 1999-2012. The results given in the text concentrate on the years at each end of the period for reasons of space.

Therefore, we believe that this analysis and the work is interesting or makes contributions of interest for the following specific reasons: first, it makes a methodological proposal based on the characteristics of the different indices and in particular, suggests their combined use for measuring seasonality in a comprehensive and more robust way: second, the measurement for Spain allows the analysis of this tourist dimension in some areas which typically exhibit high seasonality and thus permits verification of the overall effectiveness of policies; thirdly, the decomposition analysis used allows the investigation of explanatory factors as a step towards guiding possible control strategies. Here, the inequality decomposition by groups allows exploration of whether the different monthly grouping proposals can be used as a reference for policy. Furthermore, the additive decomposition of markets points to some strategic directions for reducing seasonality.

The paper is thus structured as follows: the second section reviews the main methodological aspects relating to the measurement of seasonal concentration of tourist activity, its factorial decomposition and the main data used for the implementation in the Spanish provinces cases. The third section reproduces 
the main results obtained. The final section contains the main considerations deriving from this work.

\section{Methodology and data}

Taking Butler's (1994) definition as a reference, seasonality should be measured by different intra-annual temporal imbalance - or inequality indicators. In this respect, an immediate approach would be to extract some of the learning in the literature on measuring inequality. Authors such as Chakravorty (1990) and Cowell (1995) have put forward some interesting views in this respect. Essentially, this literature has produced certain basic axioms, which all measures should satisfy, and has analysed the characteristics associated with the use of different measures. Among these, some of the most well-known are the Gini coefficient, the Theil family of indices and the CV. The essential point here is that the use of any one of these can generate different results in terms of how each one weights the distances of the different observations. This section will review the specific characteristics of the above list of measures.

First and foremost, it should be pointed out that this paper is examining the seasonal distribution of tourist activity throughout the year in the region and/or destination in question. In this respect, temporal observations, which are the basic units for the analysis, may be varied. A reasonable option would be to consider the months of the year as basic units, which would give the analysis an interesting level of detail, with the data available, and would match the typical seasonal monitoring unit of tourism companies and public administrations. In this respect, we know that it is not possible to provide even more detail on tourist activity in a homogenous way in Spain. However, it is possible to choose a more aggregated temporal base for the analysis, such as quarters, fourmonthly periods or seasons. In this respect, a certain amount of analytic precision would be lost, but on the other hand it would avoid the consequences of the calendar effect in some years, such as the positioning of Easter week. 
The key point is thus to establish the limits of these sub-periods, which is no trivial matter.

Let us suppose, for example, that the seasonal concentration of activity takes a calendar month as the unit of reference. Therefore, the inequality measures would actually be inter-monthly inequality measures of the activity. In particular, one of the most widely recommended measures (even in the literature on tourism) in this respect has been the Gini coefficient (Gini, 1912), based on the well-known Lorenz curve, which is defined as twice the area between the curve and the line of perfect equality (Wanhill, 1980; Lundtorp, 2001; Roselló et al, 2004; Fernandez-Morales, 2003 and Martin et al, 2014). One of the most conventional formulas for this measurement is the following (already adapted to the analysis of seasonal tourist concentrations):

$$
G=\frac{1}{2 \mu} \sum_{i} \sum_{j} p_{i} p_{j}\left|y_{i}-y_{j}\right|
$$

where $p_{i}$ and $p_{j}$ are the relative weights of the observations (months or seasons); $y_{i}$ is the variable for observations (in this case, tourist demand) and $\mu$ is the annual mean.

It should be noted that $\mathrm{i}$ and $\mathrm{j}$ could be any two months in the year. It should also be noted that the weightings of each observation, in their application to the analysis of seasonality, are equal for all the compared periods and equivalent to $1 / n$, where " $n$ " is the number of periods under consideration (if the periods are symmetrical). This being the case, if the analysis focuses on a monthly comparison, " $\mathrm{n}$ " is equal to 12 , while if it focuses on a four-monthly comparison, it would be 3 .

In particular, three features have been highlighted on this measure (Wanhill, 1980 or Lundtorp, 2001). First, its reduced dependence on the changes in the peak months; second, its high stability compared with other measures and third, its low sensitivity to extreme values. However, this index has a curious property: it gives greater importance to distributional changes taking place in the centre 
(mode) of the distribution (in our case, in the months of annual average demand), and gives a symmetrical weight to changes in the tails (i.e. months with higher and lower demand). In this sense, it seems reasonable not necessarily agree with this automatic behaviour. In fact, for example, in the typical income analysis, often the researchers would preferably use more "sensitive" to what occurs in the lower part of the distribution (progressive measures). If this is so also in this field, alternative measures would probably have to focus our attention, such as the Theil family of indices, which also provide a more general framework for the treatment of this aspect. In this sense, Theil (1967) proposed a family of inequality measures based on the concept of entropy in information theory. Its general expression is given by:

$$
T(\beta)=\frac{1}{\beta(\beta-1)} \sum_{i} p_{i}\left[\left(\frac{y_{i}}{\mu}\right)^{\beta}-1\right] \beta \neq 0,1
$$

Indeed, the parameter $\beta$ captures the sensitivity of the measurement to the place where the distribution changes. Specifically, the lower this value is then the measure will be more sensitive to changes in the lower ranking of observations (more progressive is the index). In the limit as $\beta$ tends to $-\infty$ the index only focuses on the lower end. In contrast, the higher is this parameter the measures is more sensitive to changes at the top of the ranking, in our case of months depending on their tourism demand. In fact, for values greater than 2 $\beta$ only seems to be sensitive to the changes among the months of highest demand (in fact, $T(2)$ is a neutral index and ordinally equivalent to the $C V$ ).

Among this family, individual indices that have enjoyed the most attention are $T(0)$ and $T(1)$, the algebraic expressions are:

$$
\begin{aligned}
& T(\beta=0)=-\sum_{i} p_{p} \log \left(\frac{\mu}{y_{i}}\right) \\
& T(\beta=1)=\sum_{i} p_{p}\left(\frac{y_{i}}{\mu}\right) \log \left(\frac{y_{i}}{\mu}\right)
\end{aligned}
$$


Finally it should be noted the advantages of the CV as a summary measure of dispersion. The $\mathrm{CV}$ is constructed by dividing the standard deviation by the mean and succeeds to fulfil the basic axioms required of any satisfactory measure. If we square and divided it in half the resulting measure is ordinally equivalent to $T(2)$. An important feature of their behaviour is that the $C V$ values evenly redistributive changes within the distribution. Therefore, it is irrelevant in relation to the specific place of the observations (the months in our case). This distributive neutrality appears quite useful for the analysis of tourism seasonality from a methodological point of view and also practical.

Therefore, each inequality index has its own characteristics associated with its sensitivity. The Gini index is sensitive to central observations; the Theil to those in the last positions of the ranking and the $\mathrm{CV}$ is neutral. The researcher should choose, when applicable, the measure that best suits their preferences and value judgments. Since there is no unanimous preference for one over the others, we recommended looking at all of them and checking whether or not they produce discrepancies in patterns, or at least in the general measurement. This paper has chosen this path.

Beyond meeting the basic properties an additional attractive of some measures is its ability to break down into parts. With regard to this possibility the inequality measurement literature has focused, until now, in two different approaches: the group decomposition and the source decomposition. In the first case, the distributive observations (in our case, the different months) are divided in groups to analyse which part of the total inequality (seasonality) can be attributed to each group. Thus, an aggregate index that can be additively decomposable could be expressed as the sum of a between-group component, which would measure the average dissimilarity among the groups, and a withingroup component, which would reflect the internal differences and, in fact, is a weighted average of the inequalities in the interior of the groups. Thus, and based on the literature on the index decomposability, an index $I$ is additively decomposable over this decomposition format if: 


$$
I=\sum_{g} w_{g} I_{g}+I_{b}
$$

where $w_{g}$ are the weights attached to each group, $I_{g}$ is the inner-inequality for each group and $I_{b}$ is the inequality among groups.

In the case of the Gini coefficient it can be shown (Zagier (1983) that the former inequality decomposition does not generally hold. Only in the cases where the groups do not overlap, or in which the inequality within the group is zero, nontrivial case in the case of the seasonality analysis, the Gini coefficient is additively decomposable in the sense pointed out by (5). This decomposition implies obtaining in the expression an additional component, which is referred as transvariation component, to solve the inequality in (5), which can be interpreted, as a test of the cohesion degree of the groups. In fact, Zaiger (1983) had already shown that the Gini coefficient can only be additively decomposable if the group distributions do not overlap among them, a very unlikely assumption. However, the test of the degree of group cohesion and the appropriateness of its definition can be directly done by the own within-group component, whose relative weight can be interpreted in terms of the error made to do the month grouping.

The family of Theil Index is always additively decomposable in the sense of (5). Shorrocks (1984) shown that the group decomposition of $\mathrm{T}(0)$ generates less ambiguity, so that:

$$
T(0)=T(0)_{w}+T(0)_{B}=\sum_{g} \frac{1}{g} T(0)_{g}+\sum_{g} \frac{1}{g} \ln \left(\frac{\mu}{y_{i}}\right)
$$

where $T(0)_{\mathrm{W}}$ is the aggregate between-groups inequality component; $T(0)_{B}$ denotes the internal inequality present in group " $g$ ". Finally, yi represents the tourism activity in month "i"; and $\mu$ is the average annual average on tourism activity indicator. 
Results derived from this decomposition analysis may be used for testing the usefulness of the selected temporal aggregation criterion. If we observe that most of the annual seasonality inequalities were attributable to intra-groups disparities we might derive that informative relevance of the month-partitions would be limited. This is because internal cohesion within the groups would be small, losing the own significance of these groupings.

In order to perform the monthly groupings there are several available options: quarters or four-month periods, so that the length of the periods is symmetric; or periods of different lengths to take into account the actual activity concentration in the different destinations. In any case, the choice of the longest periods would tend to increase the inequality inside the groups and to reduce the between groups inequality. In this paper, rather than grouping by quarters it was decided to use a 5-4-3 rule, where the first period running from January to May includes Easter and the months leading to higher demand; the second period covers the typically high demand months and runs from June to September and the final period consists of the last three months of the year ${ }^{1}$.

Also the $\mathrm{CV}$ is not decomposable in these terms. In particular, and if we take the square of $\mathrm{CV}$ the sum of the inter-group and intra-group components do not add to the global inequality, since the weights do not sum to unity. Further decomposition is ambiguous, because the weights depend, in this case, on the own weight of the demand of each month (Goerlich, 1998).

On the other side, another index decomposition that has received attention is associated to the source decomposition. In this case, it should be assessed the contribution over the total inequality by additive parts of the global component (for example in our case typically incoming markets). The methodology employed up to know in tourist applications (Fernandez-Morales and MayorgaToledano, 2008) was based on the decomposition technique for the Gini suggested by Lerman and Yitzaki (1985), which allows to decompose this

\footnotetext{
${ }^{1}$ The aggregate monthly periods can be established exogenously and globally as it is done in this paper. Therefore, it would also be possible to establish endogenous aggregates for the months, individualized for each province. Whatever the case, we believe that the four-monthly groups and the $5+4+3$ breakdown are intuitive and sufficiently illustrative at a general level.
} 
measure as the sum for each source of the product of three factors: the inequality arisen from each source (in that case the incoming market), its annual weight, and a correlative component. However, and according to Shorrocks (1982), there is no unique rule to do a factor distribution of the correlation effects and thus, the contribution of the factors to the total inequality. As a result, the contribution assigned to each component strictly depends on the way the interaction effects are allocated among contributions. This is why the literature does not consider Gini as a decomposable index in these terms (Goerlich, 1998). Then, this kind of decomposition, contrary to what happens in the group decomposition, is not quite clear. For the case of the Theil family of indexes Shorrocks (1982) derived also precise source decompositions. CV also allows it through what is called the natural decomposition of the variance. This one basically implies the quantification of the contributions to the global (seasonal) inequality that, basically, implies the quantification of the contributions to global (seasonal) inequality of each additive factor from its own dispersion and half of the affected covariances (Shorrocks, 1982). In fact, Shorrocks (1982) proves that, under some very plausible axioms ${ }^{2}$, the previous natural decomposition of the $C V^{2}$, is the only unambiguous decomposition method independently of the index used to measure whole inequality. Thus, a rule can be established where the relative contributions of each factor can be derived through the following expression (already adapted to the case of incoming markets):

$$
C_{k}=\frac{\operatorname{Var}\left(M_{k}\right)+\sum_{j \neq k} \operatorname{Cov}\left(M_{k}, M_{j}\right)}{\operatorname{Var}(M)}=\sum_{j} \operatorname{Cov}\left(M_{k}, M_{j}\right)=\operatorname{Cov}\left(M_{k}, M\right)
$$

where $C_{k}$ is the relative contribution made by incoming market $k ; M_{k}$ refers to the vector of monthly market demand k; Var is the simple variance (or weighted) and cov is the covariance.

\footnotetext{
${ }^{2}$ The conditions are: a) the inequality index and the sources are continuous and symmetric. b) The contributions do not depend on the aggregation level. c) The contributions of the factors add the global inequality. d) The contribution of source $k$ is zero if factor $k$ is evenly distributed. e) With two only factors, where one of them is a permutation of the other, the contributions must be equal.
} 
Thus, the rule which states that the weight of each source (market) concentration (monthly) tourism demand depends on a direct component, associated with the monthly market concentration itself, and an indirect component associated with its correlation with other markets. In these terms, for example, we can think hypothetically that the correlation between domestic market and foreign market can be negative, in the sense that given the concentration of the foreign market domestics may decide to go in the months of lower foreign demand, thus avoiding congestion costs.

The basic data used for doing the application to Spain comes from the Hotel Occupancy Survey of the Spanish Institute of Statistics (INE). In particular, they refer to the indicator of hotel nights, which is a reasonable and operative reflection of the impact of tourism on a region. For example, this indicator has been used by Fernandez-Morales (2003), Fernandez-Morales and MayorgaToledano (2008), Cuccia and Rizzo (2011) or Martín et al (2014), among others $^{3}$. Furthermore, the volume of overnights generated by the hotels is far greater than the one resulting from other accommodations options. In 2012, 280.7 million hotel overnights were generated nationwide - the corresponding figures were 31.3 million for camping, 7.5 million for rural tourism and 63 million for regulated apartments.

The data are distributed by months and by Spanish provinces and cover the period of 1999-2012. In the empirical analysis, the main 14 provinces were selected in terms of their annual hotel demand. In 2012, these provinces racked up over 4 million hotel nights, which as a whole represents $83 \%$ of the overall hotel demand in Spain. In order of demand, the following provinces were included: the Balearic Islands, Las Palmas, Barcelona, Santa Cruz de Tenerife, Madrid, Malaga, Alicante, Girona, Tarragona, Cadiz, Valencia, Granada, Seville and Almeria. These provinces make up the bulk of the Mediterranean coastal provinces and the islands, which typically have a strong demand for sun-sea-

\footnotetext{
${ }^{3}$ Obviously it is plausible and interesting to extend the analysis to other tourist activity indicators - for example, that of hotel supply, as was done by López and López (2006) and Capó et al. (2007).
} 
sand type vacations, plus the Spanish capital. The attached map shows their specific locations ${ }^{4}$.

\section{Map 1: Geographical location of Spanish provinces considered in the empirical analysis}

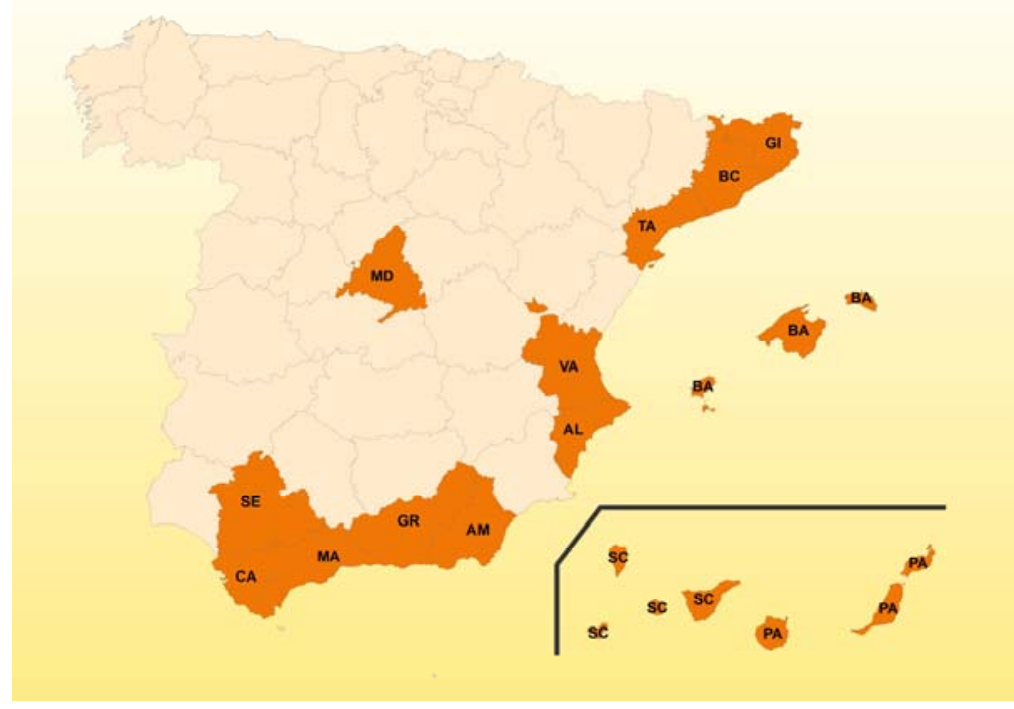

Note: $\mathrm{Al}$ is Alicante; AM is Almeria; BA is Baleares; BC is Barcelona; CA is Cadiz; GI is Girona; GR is Granada; MA is Malaga; MD is Madrid; PA is Las Palmas; SC is Santa Cruz de Tenerife; SE is Seville; TA is Tarragona and VA is Valencia Source: Derived by present authors.

\section{Empirical results for the main Spanish tourist provinces}

Before examining the seasonal factor (i.e. the concentration) at a provincial level, it is worth contextualizing these patterns in relation to the general framework of the country. For this purpose Figure 1 is attached, which represents the total annual evolution in Spain of hotel demand (hotel nights) and their monthly concentration in terms of the four inequality indices proposed in the previous section. In this respect, an average ascending pattern can be observed in the total demand, although there are variations. For example, from 2002 to 2007 , hotel demand clearly grew throughout the country, subsequently

\footnotetext{
${ }^{4}$ Mainly to save space and to facilitate obtaining relevant patterns, it was decided to focus the analysis on the major tourist provinces. Although seasonality in some of the excluded provinces may be relevant, their overall explanatory power for seasonality in Spain is small given their low relative weight on overall demand. Of the 10 provinces with the highest tourism seasonality, five are studied in the paper; in particular, the top three (the Balearics, Tarragona and Girona) are included. The author can provide all the data upon request.
} 
stabilizing before showing a marked regression in 2009 (the large tourist crisis) and then recovering through to 2011. In overall terms during this period, hotel demand in Spain grew by $22 \%$, or an annual cumulative average of $1.5 \%$. At the same time, it can be seen that the monthly concentration shows greater stability, with a smaller seasonal variation range (mainly in the case of Gini and $\mathrm{CV})$. Whatever the case, and for simplification purposes, the concentration recorded a downward path up to 2007, when it started a fairly clear upward trajectory. For example, according to the CV or the Gini coefficient $(G)$, the monthly concentration increased from 2007 by almost $10 \%$. Indeed, as a result of this last evolution, and when compared with the overall evolution across the whole period, a worsening in the concentration would have been recorded, irrespective of the inequality index under consideration. In particular, increases in concentration in the period as a whole would fluctuate between $5 \%$ and $9 \%$, according to the index. Therefore, at a domestic global level the context has been one of a worsening in the concentration, this worsening being centred on the period after 2007, which coincides with a typical phase of an increase in global demand except for the economic (tourist) crisis of 2009.

Figure 1: Changes in yearly hotel demand and its monthly concentration in Spain, 1999-2012

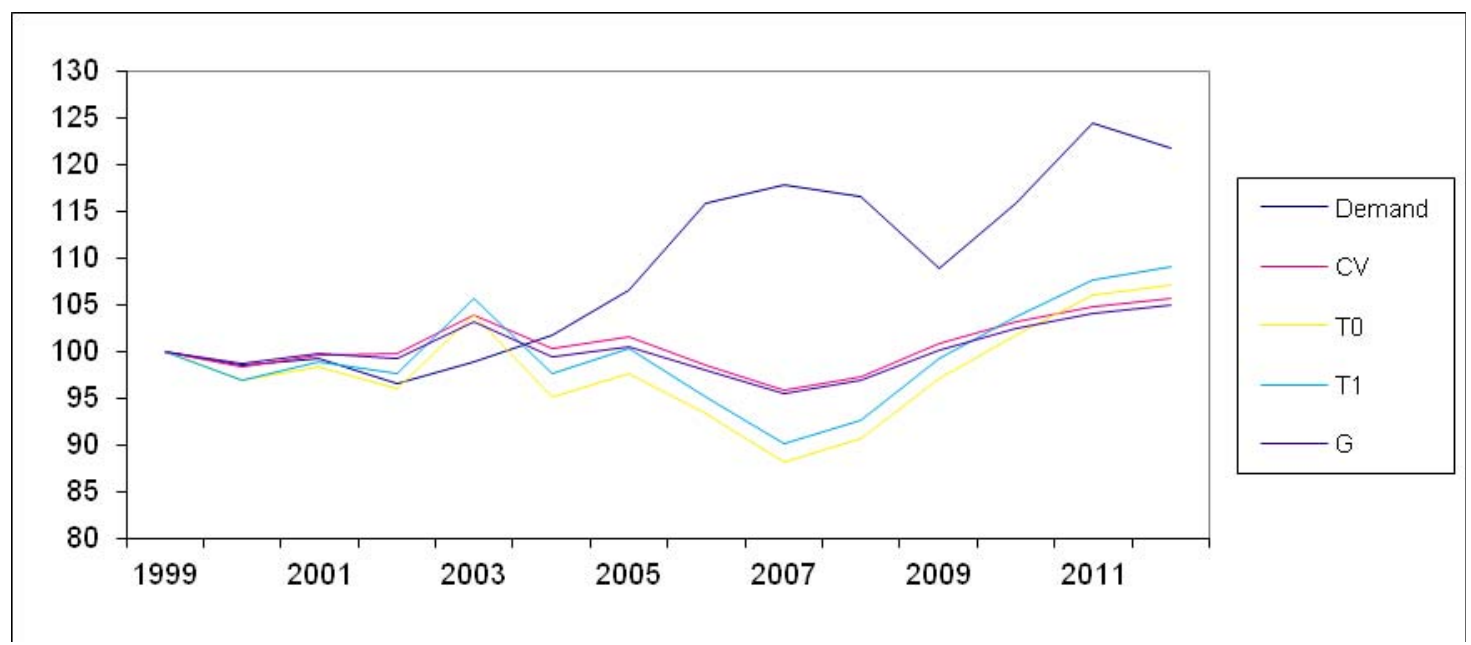

Note: data are on index numbers $(1999=100)$ : Demand is the total annual demand; $C V$ is the coefficient of variation; $T O$ and $T 1$ are the Theil indexes with this sensivity parameters and $G$ is de Gini coefficient

Source: Derived by present authors from Hotel Occupancy Survey (INE) data. 


\subsection{Results of overall concentration in the country}

In view of the above, what is the comparative seasonality of the provinces in question? Is there any difference in the measurement in terms of the concentration measure used? What has been the temporal evolution of this concentration in recent years? For this purpose, Table 1 provides the data for 2012 as well as the global evolution from 1999-2012 according to the indices. These calculations are made on a monthly basis. As a complementary exercise, and to examine the possible 'calendar impact', for instance, the results are also provided using a four-monthly base unit in Table 2 and by asymmetric monthly periods in Table 3, coinciding approximately with the general low season periods in these types of provinces (January to May and October to December) and the high season period (June to September).

Firstly, Table 1 reproduces the information relating to the concentration of hotel demand by provinces on a monthly basis. This is hypothetically the most accurate measure, but can be affected by the 'calendar impact' in some particular years and particularly by the dates of the Easter holiday. Nevertheless, we believe that it provides a useful start to the analysis. Furthermore, it should be noted that this element has no significant effect on territorial comparisons (i.e. cross-sections). In this respect, the results indicate certain interesting points. For example, the rankings typically do not vary very much when using the different concentration indices. In 2012 the most unbalanced provinces (seasonally) were unanimously the Balearic Islands, Tarragona and Girona (typical sun-sand-and-sea destinations) while the least unbalanced were the provinces of the Canary Islands (lower monthly climate variations) and Madrid, which specializes in business and cultural tourism, as well as Granada and Seville which both have a strong cultural component (e.g. World Heritage Sites) and tourist diversification. Meanwhile, in terms of evolution there was a worsening on average, although with different patterns across the provinces. For example, the Balearic Islands and Almeria were the provinces that witnessed the highest growth in monthly hotel demand concentration for the period 1999-2012 (particularly problematic in the case of 
the Balearics, given the high absolute level). Although in most cases the concentration worsened, in some cases the seasonal pattern is one of improvement. This is the case, for example, of Girona (which is following a strategy of diversification towards a more cultural tourism offering), Barcelona (the effect of being a European tourism capital and its diversification), Granada and Santa Cruz de Tenerife. Finally, in terms of the direction of the evolution, and although the indices essentially point a broadly similar direction, they typically diverge in the scale of the variation, given their different properties, and even in some specific cases even in the direction of change. For example, the latter was the case of Tarragona, whose concentration rose slightly based on the CV but dropped according to the Theil Index and slightly increased according to the Gini coefficient. Therefore, we must be careful to establish firm conclusions on the basis of a single index, not only in terms of the magnitude of evolution but sometimes even in terms of the direction of change itself.

Nevertheless, and in comparative terms, for instance, Fernandez-Morales (2003) conducted an analysis of the monthly concentration of three of our detailed provinces (Almeria, Granada and Malaga), for an earlier period (19902000), using the same demand indicator (overnights) and the Gini index. Among its key findings, the author found a reduction in concentration during this period in the case of Almeria (sun and beach) and Granada (diversity of product) and stabilization in the case of Málaga (sun and beach). In contrast, our results indicate a worsening for Almeria and Malaga, both highly specialized products sun and sand, but a new improvement in the case of Granada.

In addition, Figure 2 reproduces the entire time series of monthly concentration of demand for provinces with a higher than national average seasonality in 2012; Figure 3 concerns those with below average seasonality. To save space, we only offer results from the $\mathrm{CV}$, the neutral index. ${ }^{5}$ Firstly, we note that in general the range of variation of the concentration is not particularly high over time. In fact, the variation in concentration is clearly higher if we compare

\footnotetext{
${ }^{5}$ Because this is a complementary analysis and it is necessary to save space, we have decided only to offer the results from CV. Nevertheless, If we extend the temporal (yearly) analysis to the other concentration measures, there would not be significant overall qualitative differences in the selected provinces. Results available on request.
} 
provinces. This stability can be attributed partly, but only partly, to the index itself. In fact, it is not easy to change the concentration much in the short term. Secondly, if we focus on the provinces with the highest concentration, a monotonic increasing comparative pattern for the Balearic Islands can be seen (again really a disturbing pattern), a clear progression may be observed (mainly since 2007) for Cadiz and Almeria, both specialized mainly in sun-sand-beach. The decrease in concentration experienced by Girona, especially until 2008, is noteworthy. In the cases of Málaga, Alicante or Valencia (all coastal provinces and specialized in sun and beach) there is a slightly increase and, finally, in Tarragona the pattern is fundamentally stable, albeit including a record high. Thirdly, in regard to the provinces with lower monthly concentration (relative to the Spanish mean), no very clear patterns emerge. However, for the two Canary provinces, Las Palmas increased until 2010 and then declined while, in Santa Cruz de Tenerife there was an increase until 2005 and a subsequent decrease which emerged at the end of the period with the lowest tourist concentration.

So, monthly results indicate that coastal provinces typically specializing in sun and beach, with the exception of Catalan provinces, recorded a worsening of seasonality in the period. This seems to indicate the relevance of a regional factor in explaining the difference and might, in part, be attributable to policy. 
Table 1: Monthly concentration of hotel demand in major Spanish tourist provinces according to different measures, 1999 and 2012

\begin{tabular}{|l|cc|cc|cc|cc|}
\hline & CV. & & Theil-0 & & Theil-1 & & Gini & \\
\hline & $\mathbf{1 9 9 9}$ & $\mathbf{2 0 1 2}$ & $\mathbf{1 9 9 9}$ & $\mathbf{2 0 1 2}$ & $\mathbf{1 9 9 9}$ & $\mathbf{2 0 1 2}$ & $\mathbf{1 9 9 9}$ & $\mathbf{2 0 1 2}$ \\
\hline Balearic Islands & 0.6556 & 0.8824 & 0.3036 & 0.7210 & 0.2375 & 0.4402 & 0.3650 & 0.4906 \\
Tarragona & 0.8595 & 0.8692 & 0.6604 & 0.5708 & 0.4211 & 0.4029 & 0.4783 & 0.4800 \\
Girona & 0.8556 & 0.7596 & 0.4937 & 0.3473 & 0.3739 & 0.2867 & 0.4706 & 0.4194 \\
Almeria & 0.4167 & 0.6738 & 0.0874 & 0.2223 & 0.0849 & 0.2098 & 0.2338 & 0.3619 \\
Cadiz & 0.4765 & 0.5976 & 0.1268 & 0.2136 & 0.1153 & 0.1830 & 0.2672 & 0.3367 \\
Malaga & 0.3293 & 0.4343 & 0.0589 & 0.1091 & 0.0555 & 0.0983 & 0.1872 & 0.2469 \\
Barcelona & 0.4206 & 0.3662 & 0.0964 & 0.0728 & 0.0900 & 0.0684 & 0.2391 & 0.2085 \\
Alicante/Alacant & 0.2321 & 0.3352 & 0.0268 & 0.0559 & 0.0267 & 0.0551 & 0.1311 & 0.1877 \\
Valencia/València & 0.2091 & 0.3250 & 0.0228 & 0.0548 & 0.0222 & 0.0528 & 0.1167 & 0.1840 \\
Seville & 0.2208 & 0.2194 & 0.0267 & 0.0241 & 0.0253 & 0.0239 & 0.1247 & 0.1245 \\
Granada & 0.1817 & 0.1572 & 0.0174 & 0.0133 & 0.0168 & 0.0128 & 0.1036 & 0.0881 \\
Palmas, Las & 0.0768 & 0.1151 & 0.0029 & 0.0064 & 0.0029 & 0.0065 & 0.0430 & 0.0629 \\
Madrid & 0.1174 & 0.1084 & 0.0070 & 0.0059 & 0.0069 & 0.0059 & 0.0663 & 0.0614 \\
Santa Cruz Tenerife & 0.0952 & 0.0744 & 0.0044 & 0.0028 & 0.0045 & 0.0028 & 0.0514 & 0.0419 \\
\hline SPAIN & $\mathbf{0 . 3 8 2 1}$ & $\mathbf{0 . 4 0 3 7}$ & $\mathbf{0 . 0 7 7 5}$ & $\mathbf{0 . 0 8 3 1}$ & $\mathbf{0 . 0 7 3 7}$ & $\mathbf{0 . 0 8 0 4}$ & $\mathbf{0 . 2 1 6 7}$ & $\mathbf{0 . 2 2 7 3}$ \\
\hline
\end{tabular}

Note: provinces sorted in descending order based on the value of CV (neutral index) at 2012.

Source: Derived by present authors from Hotel Occupancy Survey (INE) data.

Figure 2: Changes in yearly hotel demand and its monthly concentration (for Spanish provinces that had above average seasonality in 2012), 19992012

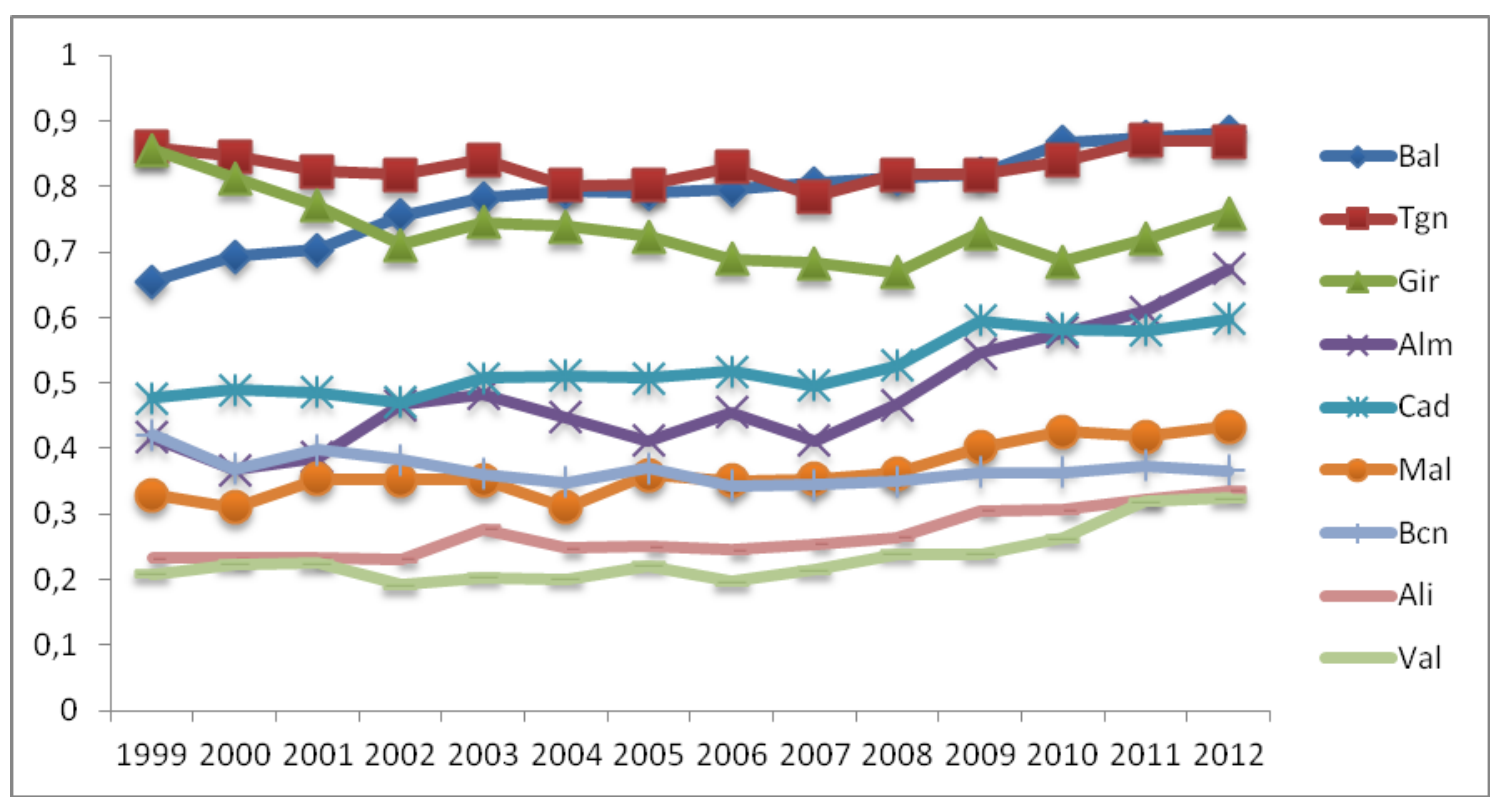

Note: Bal is Balearic Islands; Tgn is Tarragona; Gir is Girona; Alm is Almeria; Cad is Cadiz; Mal is Malaga; Bcn is Barcelona; Ali is Alicante and Val is Valencia.

Source: Derived by present authors from Hotel Occupancy Survey (INE) data. 
Figure 3: Changes in yearly hotel demand and its monthly concentration (for Spanish provinces that had below average seasonality in 2012), 19992012

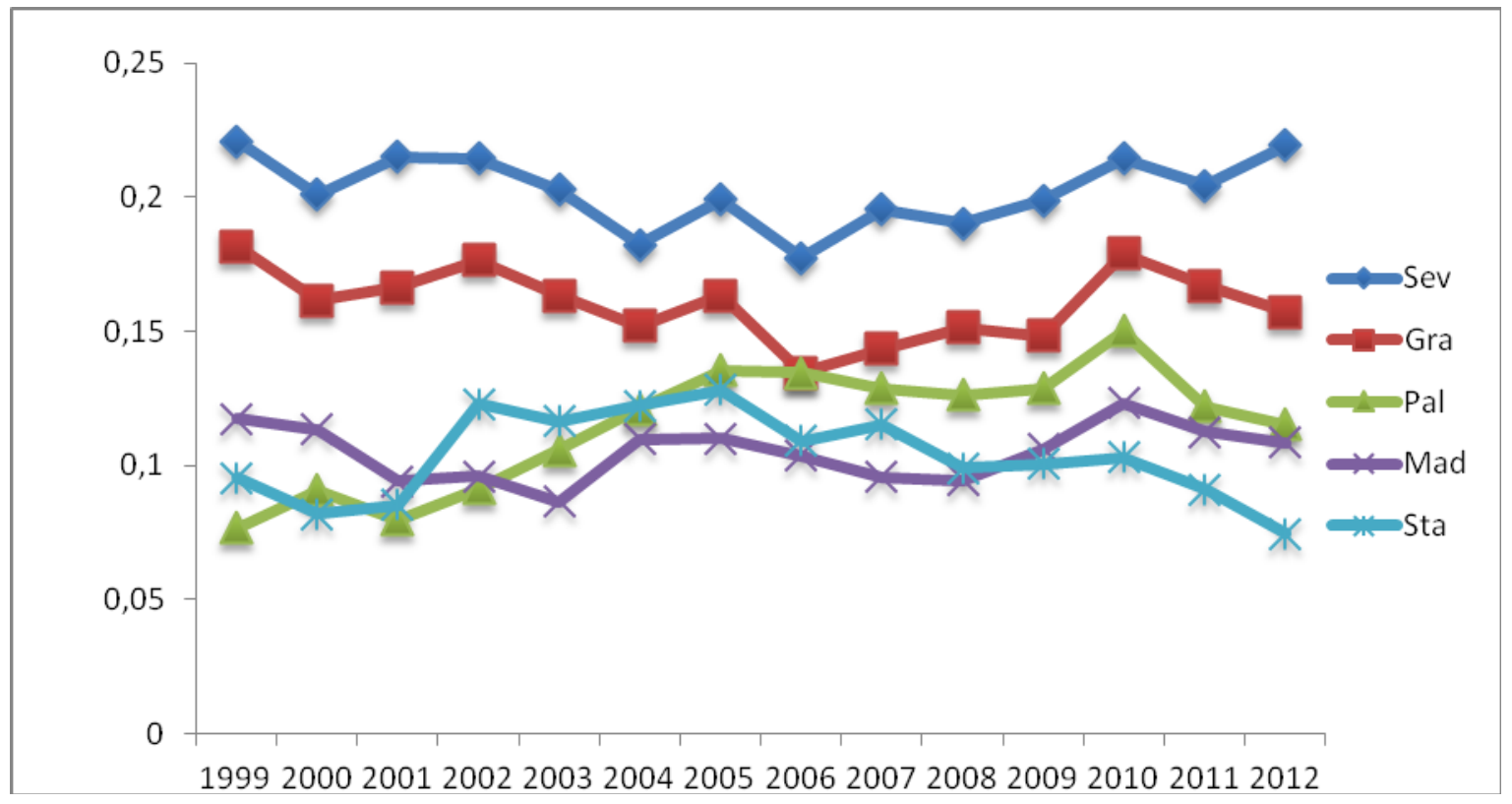

Note: Sev is Seville; Gra is Granada; Pal is Palmas; Mad is Madrid; Sta is Santa Cruz de Tenerife.

Source: Derived by present authors from Hotel Occupancy Survey (INE) data.

Table 2 shows the same analysis than in Table 1 but based on four-monthly periods. Consequently the results are less detailed yet involve two additional factors. Firstly, calculations on a four-monthly basis can avoid the impact of the measurement of holiday periods and their different positions depending on the year in question. Secondly, given that the analysis units are more aggregate, the concentration index values generate lower figures. The context is once again one of an increase in global concentration over the period. With regard to the rankings, most of the positions are generally maintained when compared to those computed on a monthly basis. For example, the Balearic Islands, Tarragona and Girona emerge as the most unbalanced provinces while the Canary Islands (Las Palmas and Santa Cruz) are the least unbalanced. However, there are some specific differences; for example, Madrid's position worsened. In terms of evolution, if a comparison is made between the indices they are broadly similar, although it is possible to find discrepancies in a detailed scale. Meanwhile, a temporal comparison of the evolution of the indices on a four-monthly and monthly basis generally points also same direction, with 
certain exceptions such as Granada, whose imbalance is smaller on a monthly basis yet increases with the four-monthly one.

Table 2: Quarterly concentration of hotel demand in major Spanish tourist provinces, according to different measures, 1999 and 2012

\begin{tabular}{|l|cc|cc|cc|cc|}
\hline & CV & & Theil-0 & & Theil-1 & & Gini & \\
\hline & $\mathbf{1 9 9 9}$ & $\mathbf{2 0 1 2}$ & $\mathbf{1 9 9 9}$ & $\mathbf{2 0 1 2}$ & $\mathbf{1 9 9 9}$ & $\mathbf{2 0 1 2}$ & $\mathbf{1 9 9 9}$ & $\mathbf{2 0 1 2}$ \\
\hline Balearic Islands & 0.5191 & 0.7160 & 0.1416 & 0.3098 & 0.1335 & 0.2610 & 0.2764 & 0.3797 \\
Tarragona & 0.6857 & 0.6935 & 0.2858 & 0.2590 & 0.2412 & 0.2354 & 0.3657 & 0.3615 \\
Girona & 0.6708 & 0.5584 & 0.2284 & 0.1553 & 0.2160 & 0.1504 & 0.3453 & 0.2908 \\
Cadiz & 0.3424 & 0.4430 & 0.0562 & 0.0924 & 0.0567 & 0.0934 & 0.1796 & 0.2274 \\
Almeria & 0.3073 & 0.4377 & 0.0438 & 0.0869 & 0.0451 & 0.0898 & 0.1558 & 0.2147 \\
Malaga & 0.2321 & 0.3160 & 0.0258 & 0.0463 & 0.0262 & 0.0477 & 0.1220 & 0.1602 \\
Barcelona & 0.3361 & 0.2719 & 0.0577 & 0.0353 & 0.0563 & 0.0358 & 0.1813 & 0.1423 \\
Alicante/Alacant & 0.1607 & 0.2421 & 0.0125 & 0.0276 & 0.0127 & 0.0283 & 0.0848 & 0.1246 \\
Valencia/València & 0.1028 & 0.2230 & 0.0053 & 0.0230 & 0.0053 & 0.0238 & 0.0559 & 0.1061 \\
Granada & 0.0584 & 0.0693 & 0.0017 & 0.0024 & 0.0017 & 0.0024 & 0.0318 & 0.0372 \\
Madrid & 0.0334 & 0.0305 & 0.0006 & 0.0005 & 0.0006 & 0.0005 & 0.0182 & 0.0160 \\
Seville & 0.0742 & 0.0286 & 0.0029 & 0.0004 & 0.0028 & 0.0004 & 0.0356 & 0.0156 \\
Palmas & 0.0150 & 0.0261 & 0.0001 & 0.0003 & 0.0001 & 0.0003 & 0.0074 & 0.0142 \\
Granada & 0.0584 & 0.0693 & 0.0017 & 0.0024 & 0.0017 & 0.0024 & 0.0318 & 0.0372 \\
Santa Cruz Tenerife & 0.0097 & 0.0229 & 0.0000 & 0.0003 & 0.0000 & 0.0003 & 0.0052 & 0.0109 \\
\hline SPAIN & $\mathbf{0 . 2 8 9 4}$ & $\mathbf{0 . 3 0 5 9}$ & $\mathbf{0 . 0 4 0 9}$ & $\mathbf{0 . 0 4 4 6}$ & $\mathbf{0 . 0 4 1 0}$ & $\mathbf{0 . 0 4 5 2}$ & $\mathbf{0 . 1 5 4 0}$ & $\mathbf{0 . 1 5 9 8}$ \\
\hline
\end{tabular}

Note: provinces sorted in descending order based on the value of CV (neutral index) at 2012.

Source: Derived by present authors from Hotel Occupancy Survey (INE) data.

Table 3 shows the analysis with a different aggregate separation, i.e. considering three heterogeneous periods spanning a first period from January to May, a second one typical of the high season, from June to September, and a final low season period, from October to December. In this respect, the results indicate that: first, overall, the ascending pattern of seasonal concentration remains the same, except for the Gini; second, although there are certain changes in the ranking, these are not dramatic ones. In any event, it is worth highlighting the changes experienced by Seville, which comparatively is better positioned using the periodic basis than in monthly terms, but the change is not dramatic; third, in general evolutionary terms, there are no major discrepancies between these calculations and those deriving from a monthly base unit. Perhaps the most notable cases are those of Granada (whose concentration drops with the monthly base unit and increases when the $5+4+3$ breakdown is used), Seville and Madrid (the same evolution as Granada). Thus, with these calculations, the territorial image of a growth in seasonality is more general; 
fourth, in this case, significant discrepancies in evolution can be observed in some provinces, depending on the index chosen. For example, Cadiz, Malaga, Alicante, Granada, Las Palmas and Seville show different types of variations depending on the index used. Typically, these discrepancies are between the Gini Coefficient and the others. So, in this case the particular choice of an index is more important that in the previous cases.

Table 3: Concentration of hotel demand by seasons $(5+4+3)$ in major Spanish tourist provinces, according to different measures, 1999 and 2012

\begin{tabular}{|l|cc|cc|cc|cc|}
\hline & CV & & Theil-0 & & Theil-1 & Gini & \\
\hline & $\mathbf{1 9 9 9}$ & $\mathbf{2 0 1 2}$ & $\mathbf{1 9 9 9}$ & $\mathbf{2 0 1 2}$ & $\mathbf{1 9 9 9}$ & $\mathbf{2 0 1 2}$ & $\mathbf{1 9 9 9}$ & $\mathbf{2 0 1 2}$ \\
\hline Tarragona & 0.7558 & 0.8016 & 0.2682 & 0.3048 & 0.2644 & 0.2932 & 0.5384 & 0.4980 \\
Balearic Islands & 0.5426 & 0.7957 & 0.1340 & 0.2981 & 0.1371 & 0.2902 & 0.4567 & 0.4775 \\
Girona & 0.7566 & 0.6739 & 0.2782 & 0.2066 & 0.2680 & 0.2069 & 0.5979 & 0.4150 \\
Almeria & 0.3673 & 0.6221 & 0.0621 & 0.1857 & 0.0639 & 0.1754 & 0.3892 & 0.4407 \\
Cadiz & 0.3754 & 0.5196 & 0.0640 & 0.1200 & 0.0663 & 0.1227 & 0.3640 & 0.3304 \\
Málaga & 0.2649 & 0.3680 & 0.0323 & 0.0599 & 0.0335 & 0.0615 & 0.3073 & 0.2461 \\
Barcelona & 0.3542 & 0.3048 & 0.0569 & 0.0417 & 0.0591 & 0.0432 & 0.3108 & 0.1892 \\
Alicante/Alacant & 0.1862 & 0.2874 & 0.0162 & 0.0370 & 0.0167 & 0.0384 & 0.2565 & 0.1803 \\
Valencia/València & 0.1519 & 0.2819 & 0.0109 & 0.0353 & 0.0112 & 0.0358 & 0.2294 & 0.2010 \\
Granada & 0.0882 & 0.1134 & 0.0041 & 0.0056 & 0.0040 & 0.0055 & 0.2729 & 0.0960 \\
Palmas & 0.0259 & 0.0613 & 0.0003 & 0.0020 & 0.0003 & 0.0020 & 0.1563 & 0.0386 \\
Seville & 0.0319 & 0.0419 & 0.0005 & 0.0008 & 0.0005 & 0.0007 & 0.1631 & 0.0378 \\
Madrid & 0.0090 & 0.0153 & 0.0000 & 0.0001 & 0.0000 & 0.0001 & 0.1580 & 0.0101 \\
Santa Cruz Tenerife & 0.0267 & 0.0112 & 0.0004 & 0.0001 & 0.0004 & 0.0001 & 0.1772 & 0.0082 \\
\hline SPAIN & 0.3199 & 0.3574 & 0.0466 & 0.0570 & 0.0484 & 0.0592 & 0.3266 & 0.2205 \\
\hline
\end{tabular}

Note: Provinces sorted in descending order based on the value of CV (neutral index) at 2012. The monthly structuring $5+4+3$ indicates three monthly groups: one from January to May (5 months); another from June to September (4 months) and, finally, October to December.

Source: Derived by present authors from Hotel Occupancy Survey (INE) data.

Nevertheless, despite the variations, when examining the changes in detail or by scale, the bulk of the overall results do not seem to vary excessively according to whether the seasonal concentration of hotel demand is ascertained on a monthly, four-monthly or seasonal basis. It typically worsens in most of Spain's main tourist provinces. However, there are notable exceptions, such as the provinces of Girona and Barcelona, both of which are coastal and yet despite specializing in sun-sand-and-sea type tourism stand out for their strong positioning in the cultural and heritage sector. Similarly, the ranking of provinces in the last year for which reliable data are available is headed by the Balearic Islands, Tarragona and Girona; in contrast, provinces such as Santa Cruz de 
Tenerife and Las Palmas (i.e., the Canary Islands), with a year-round mild climate, and Granada and Seville (with a strong cultural component) and Madrid (business tourism and the capital city) show very much lower imbalances. On the other hand, the choice of index typically does not yield very different results, perhaps with the exception of seasonal analysis $(5+4+3)$, where discrepancies are observed mainly between the Gini and the other measures in the case of six provinces.

\subsection{Decomposing seasonality}

Table 4 shows the decomposition by monthly groups (seasons) of the monthly concentration of hotel demand in the main Spanish provinces based on the results obtained from the Theil Index $(T(0))$. It should be remembered that the choice of this index for this exercise was mainly based on its facility to be decomposed and its lack of ambiguity with regard to this type of decomposition (instead using, for example, the Gini coefficient. See section 2). In this respect, the results reveal some interesting points:

Firstly, the monthly groupings are quite important as an explanatory element of seasonal concentration. In the country as a whole, the four-monthly segmentation explains more than half the global concentration. The explanatory capacity of structuring by periods $(5+4+3)$ is even higher, having increased its weight by up to almost $70 \%$ of global inequalities in 2012 .

Secondly, as is to be expected, there are regional differences. Typically, the groups used are more important in the cases in which the global concentration is more important, which is to be expected. This being the case, in most of the provinces where seasonality is higher, the groupings are significant as an element of synthesis. The case of Almeria, for example, stands out, where the segmentation of $5+4+3$ explains $84 \%$ of the monthly concentration. On the other side of the coin, there are the provinces of Seville, Madrid and Santa Cruz, where the groups barely have any explanatory capacity.

Thirdly, in relation to the variations in the concentration and in the role of the group components, it is obvious that a single pattern cannot be established. Whatever the case, it is true that typically the role of the between component, 
which is the one that justifies the explanatory capacity of this decomposition, is important. For example, in the four-monthly evaluation, the changes in the between component explain more than $40 \%$ of the growth in concentration in provinces such as the Balearic Islands, Cadiz, Malaga and Alicante. For example, this group component explains half the reduction in the monthly concentration that took place in Girona. Indeed, the inter-group component in this case explains two-thirds of the overall increase in Spain. FernandezMorales (2003) also decomposed seasonality by groups but considered differentially the possibility that months are not consecutive and used the Gini index as a reference measure for three of our provinces (Malaga, Granada and Almeria) and for an earlier period. In this case, given the flexibility of forming groups, which are different in each province, the weight of between-inequality component is typically higher. Nevertheless, we believe that, in terms of policy, it is more reasonable that the months be consecutive in each group. 
Table 4: Decomposing of monthly concentration of hotel demand by subgroups (Theil index)

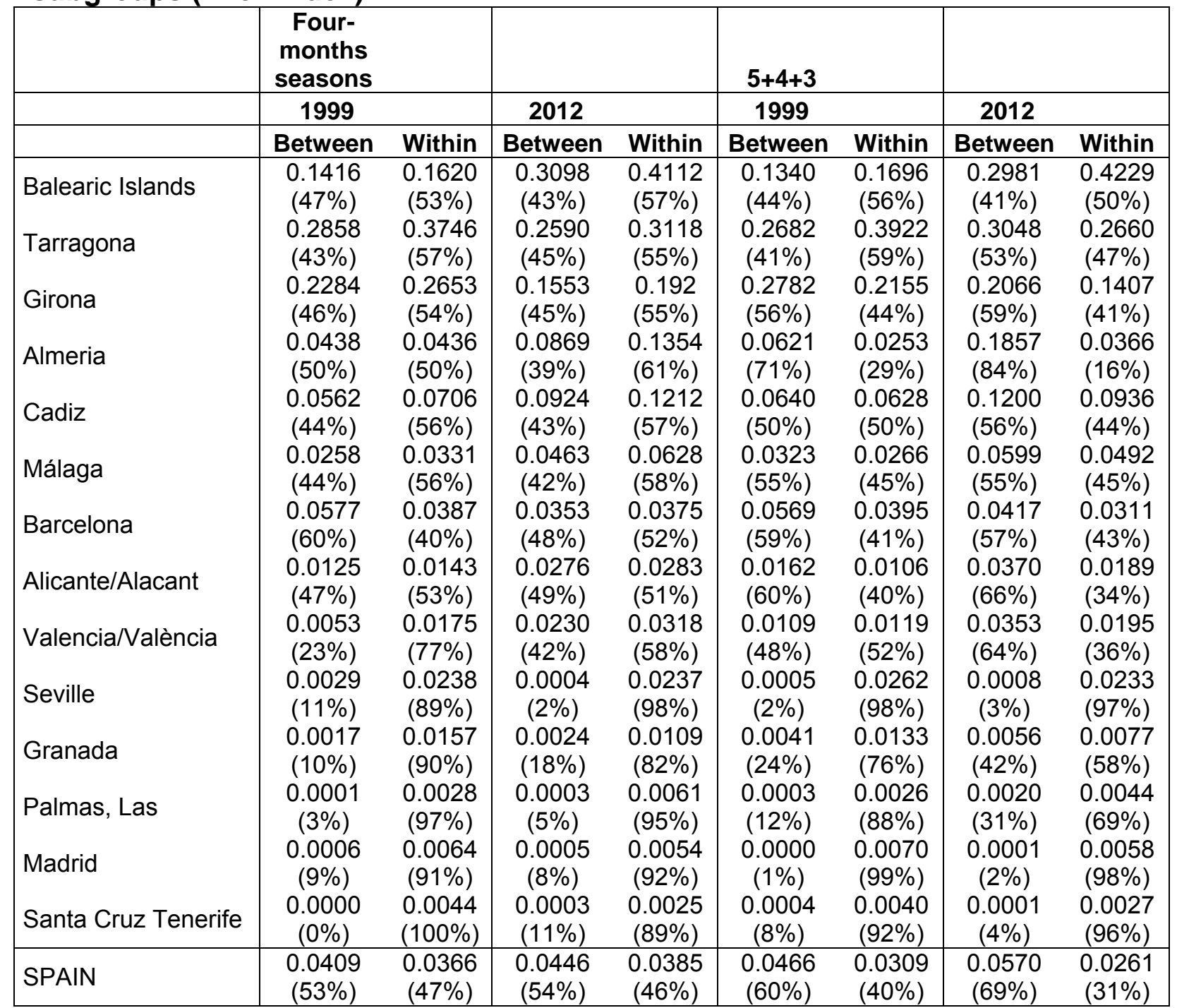

Note: The monthly structuring $5+4+3$ indicates three monthly groups: one from January to

May (5 months); another from June to September (4 months) and, finally, October to December.

Source: Derived by present authors from Hotel Occupancy Survey (INE) data.

Meanwhile, Table 5 shows the main results emerging from the decomposition of the monthly concentration by additive sources; in this case, by major markets (i.e. domestic as opposed to international). The distinction is interesting because the behaviour in terms of seasonality and the overall explanatory role may be different. For instance, domestic tourists have more access to houses, more knowledge about national destinations, typically domestic prices are lower than the international ones and also we can find differences in terms of the average stay and daily expenditures. Ex-ante, we may expect less seasonality among domestic tourists that for international ones. 
The results stem from the use of the natural variance decomposition rule, which provides the total contribution of each factor as the addition of its individual variance and the cross-covariance. It can be seen that the decomposition could have been specified much more at the level of source markets, but our understanding was that as a first analysis it could be sufficient. In fact it can be surmised a priori that the majority of the differences in the monthly concentration of markets would be attributable to the domestic versus international market binomial. Table 6 also details the role of the direct component (the individual variation) and the indirect component (the covariance between the two large markets) in explaining the relative contribution of each major market. It can be seen that, in this case, it is interesting to know the sign and relevance of the correlation and, consequently, to verify whether the two markets strengthen the monthly concentration or not. Table 7 , meanwhile, reproduces two of the main factors that would be behind the direct component, i.e. the weighting and the individual variation, in this case approximate, for the CV. In particular, the main results obtained can be summed up in the following points:

Firstly, seasonality can be explained nationwide by the foreign component. Thus in the case of Spain as a whole, the foreign market explains approximately $70 \%$ of the seasonal concentration. This is due to its greater global weighting and its higher monthly concentration as compared to the domestic market.

Secondly, the main factor behind these weightings, especially if they are large, is typically the direct component. Whatever the case, the indirect component always has a positive value, which is indicative of the fact that both markets strengthen each other in determining the concentration, so without any significant compensatory effect between the domestic and international markets being observed. Indeed, in seven of the Spanish provinces analysed, the domestic market concentration is even higher that the international one (Table 7 ), in contrast to the previous standard view. In particular, this is the case in coastal sun and beach provinces (except the Catalan ones) and the Canary Islands provinces. Therefore, the increase in the domestic market role in the provinces would not necessarily reduce seasonality in all of them. It depends on the particular province. 
Thirdly, focusing now on the direct effect, the documented increase in the country's seasonal concentration would be attributable, above all, to the increase in the monthly concentration experienced in the two major markets, i.e. the individual seasonal variation (indicated in Table 7 by the CV).

Fourthly, focusing now on the territorial analysis, in most of the provinces under consideration the foreign market is the main generator of concentration, in line with the results obtained at an aggregate level. Only in the cases of Almeria, Cadiz, Alicante and Valencia is the domestic market the main protagonist. In all these cases, this role is attributed both to the yearly weight of the domestic market as to the differential seasonality of this market regarding international one.

As point five, when the evolution is examined, there is a very significant increase in the weighting of the foreign component in regions such as Tarragona, Alicante, Valencia, Seville, Madrid and Santa Cruz de Tenerife. In all these regions, the weighting of the foreign market increases and also it is observed a worsening of their individual concentrations, except in case of Madrid (see Table 7).

In sixth place, in the provinces of Almeria and Las Palmas it is the domestic component whose participation increases, in both cases due to the combined effect of its weighting and individual concentration.

Table 5: Decomposing monthly concentration by relative contribution of large markets, 1999 and 2012

\begin{tabular}{|l|cc|cc|}
\hline & $\mathbf{1 9 9 9}$ & & $\mathbf{2 0 1 2}$ & \\
\hline & Domestic & International & Domestic & International \\
\hline Balearic Islands & 0,0308 & 0,9692 & 0,0524 & 0,9476 \\
Tarragona & 0,3458 & 0,6542 & 0,2993 & 0,7007 \\
Girona & 0,1782 & 0,8218 & 0,2062 & 0,7938 \\
Almeria & 0,5686 & 0,4314 & 0,8294 & 0,1706 \\
Cadiz & 0,5906 & 0,4094 & 0,6319 & 0,3681 \\
Málaga & 0,3491 & 0,6509 & 0,3897 & 0,6103 \\
Barcelona & 0,0993 & 0,9007 & 0,0798 & 0,9202 \\
Alicante/Alacant & 0,8558 & 0,1442 & 0,6083 & 0,3917 \\
Valencia/València & 0,7595 & 0,2405 & 0,6397 & 0,3603 \\
Seville & 0,3592 & 0,6408 & 0,2821 & 0,7179 \\
Granada & 0,3951 & 0,6049 & 0,4252 & 0,5748 \\
Palmas, Las & 0,2672 & 0,7328 & 0,3887 & 0,6113 \\
Madrid & 0,2998 & 0,7002 & 0,2459 & 0,7541 \\
Santa Cruz Tenerife & 0,4462 & 0,5538 & 0,1859 & 0,8141 \\
\hline SPAIN & $\mathbf{0 , 2 8 4 5}$ & $\mathbf{0 , 7 1 7 1}$ & $\mathbf{0 , 3 0 2 8}$ & $\mathbf{0 , 6 9 7 8}$ \\
\hline
\end{tabular}

Source: Derived by present authors from Hotel Occupancy Survey (INE) data. 
Table 6: Decomposing monthly concentration by relative contribution of large markets, 1999 and 2012 and by direct and indirect components

\begin{tabular}{|c|c|c|c|c|c|c|}
\hline & \multicolumn{3}{|c|}{1999} & \multicolumn{3}{|c|}{2012} \\
\hline & $\begin{array}{l}\text { Dom. } \\
\text { Direct }\end{array}$ & $\begin{array}{c}\text { Int. } \\
\text { Direct }\end{array}$ & Indirect & $\begin{array}{l}\text { Dom. } \\
\text { Direct }\end{array}$ & $\begin{array}{c}\text { Int. } \\
\text { Direct }\end{array}$ & Indirect \\
\hline Balearic Islands & 0,0023 & 0,9407 & 0,0285 & 0,0042 & 0,8993 & 0,0482 \\
\hline Tarragona & 0,1307 & 0,4392 & 0,2151 & 0,0968 & 0,4982 & 0,2025 \\
\hline Girona & 0,0390 & 0,6825 & 0,1393 & 0,0509 & 0,6385 & 0,1553 \\
\hline Almeria & 0,3829 & 0,2458 & 0,1856 & 0,6940 & 0,0352 & 0,1354 \\
\hline Cadiz & 0,3897 & 0,2084 & 0,2010 & 0,4309 & 0,1671 & 0,2010 \\
\hline Málaga & 0,1476 & 0,4493 & 0,2015 & 0,1945 & 0,4150 & 0,1953 \\
\hline Barcelona & 0,0130 & 0,8144 & 0,0863 & 0,0092 & 0,8496 & 0,0706 \\
\hline Alicante/Alacant & 0,7477 & 0,0361 & 0,1081 & 0,3962 & 0,1796 & 0,2121 \\
\hline Valencia/València & 0,5959 & 0,0768 & 0,1637 & 0,4209 & 0,1415 & 0,2188 \\
\hline Seville & 0,1652 & 0,4468 & 0,1940 & 0,1302 & 0,5660 & 0,1519 \\
\hline Granada & 0,3191 & 0,5289 & 0,0760 & 0,3316 & 0,4813 & 0,0936 \\
\hline Palmas, Las & 0,1427 & 0,6084 & 0,1244 & 0,2996 & 0,5222 & 0,0891 \\
\hline Madrid & 0,1682 & 0,5687 & 0,1315 & 0,1115 & 0,6197 & 0,1344 \\
\hline Santa Cruz Tenerife & 0,4232 & 0,5308 & 0,0230 & 0,4487 & 1,0770 & $-0,2629$ \\
\hline SPAIN & 0,0932 & 0,5258 & 0,1913 & 0,1016 & 0,4965 & 0,2012 \\
\hline
\end{tabular}

Note: relative weights of total variance. In the case of the indirect component is the total weight, which would be symetrically allocated by each market.

Source: Derived by present authors from Hotel Occupancy Survey (INE) data.

Table 7: Decomposing monthly concentration by large markets, 1999 and 2012. Explanatory Factors.

\begin{tabular}{|l|cc|cc|cc|cc|}
\hline & $\mathbf{1 9 9 9}$ & & & & $\mathbf{2 0 1 2}$ & & & \\
\hline & \%Dom & CV Dom & \%Int & CV Int & \%Dom & CV Dom & \%Int & CV Int \\
\hline Balearic Islands & 0,0960 & 1,1447 & 0,9040 & 2,4367 & 0,0885 & 2,2282 & 0,9115 & 3,1802 \\
Tarragona & 0,3945 & 2,7287 & 0,6055 & 3,2585 & 0,3789 & 2,4731 & 0,6211 & 3,4214 \\
Girona & 0,2508 & 2,3329 & 0,7492 & 3,2682 & 0,2900 & 2,0461 & 0,7100 & 2,9617 \\
Almeria & 0,4790 & 1,8650 & 0,5210 & 1,3735 & 0,7850 & 2,4771 & 0,2150 & 2,0383 \\
Cadiz & 0,5249 & 1,9631 & 0,4751 & 1,5864 & 0,5678 & 2,3931 & 0,4322 & 1,9582 \\
Málaga & 0,2899 & 1,5121 & 0,7101 & 1,0769 & 0,3371 & 1,9680 & 0,6629 & 1,4618 \\
Barcelona & 0,3116 & 0,5331 & 0,6884 & 1,9100 & 0,2219 & 0,5495 & 0,7781 & 1,5027 \\
Alicante/Alacant & 0,4384 & 1,5860 & 0,5616 & 0,2719 & 0,5429 & 1,3462 & 0,4571 & 1,0767 \\
Valencia/València & 0,7749 & 0,7214 & 0,2252 & 0,8914 & 0,6188 & 1,1801 & 0,3812 & 1,1107 \\
Seville & 0,5144 & 0,6043 & 0,4856 & 1,0526 & 0,4651 & 0,5897 & 0,5349 & 1,0690 \\
Granada & 0,5407 & 0,6575 & 0,4593 & 0,9965 & 0,5990 & 0,5235 & 0,4010 & 0,9422 \\
Palmas, Las & 0,1099 & 0,9151 & 0,8901 & 0,2332 & 0,1343 & 1,6252 & 0,8657 & 0,3328 \\
Madrid & 0,5237 & 0,3186 & 0,4763 & 0,6441 & 0,5009 & 0,2504 & 0,4991 & 0,5924 \\
Santa Cruz Tenerife & 0,2011 & 1,0664 & 0,7989 & 0,3007 & 0,1809 & 0,9544 & 0,8191 & 0,3266 \\
\hline SPAIN & $\mathbf{0 , 3 5 4 1}$ & $\mathbf{1 , 1 4 1 1}$ & $\mathbf{0 , 6 4 7 4}$ & $\mathbf{1 , 4 8 2 5}$ & $\mathbf{0 , 3 6 4 2}$ & $\mathbf{1 , 2 2 4 2}$ & $\mathbf{0 , 6 3 6 8}$ & $\mathbf{1 , 5 4 7 4}$ \\
\hline
\end{tabular}

Source: Derived by present authors from Hotel Occupancy Survey (INE) data.

Finally, Table 8 reproduces in detail the decomposition of the concentration by individual markets, apart from the major markets shown in Table 5. In relation to the domestic market, its weighting in the concentration stands out, providing 
$30 \%$ of the monthly concentration. This is followed by the British market $(20 \%)$ and the German market (17\%), in that order. Therefore these three markets account for two-thirds of the global concentration in Spain, and must be given priority in the strategy of fighting this inequality on a global scale. Obviously, looking down the list different patterns can be seen, fundamentally attributable to the weighting of these markets in the annual global demand. To mention a few of the cases that differ from the overall pattern, it is first worth highlighting the case of the Balearic Islands, where the German and British markets are the main generators of concentration (jointly explaining $66 \%$ of the monthly concentration in this province) while the domestic market has a relatively low weighting. Indeed, Roselló et al. (2004) analysed the pattern of seasonality of the British and German markets for the period 1982-2001 in the case precisely of the Balearic Islands. They found, for example, a growing seasonality for the British market in the islands, but a decreasing one in the German case. Moreover, in both cases it was found that income and prices acted to reduce and increase seasonality, respectively and also that that Germans are less price sensitive than the English and also, in the short term, with regard to income. On the other hand, in the case of the province of Tarragona, the rise in Russian tourism has led to this particular market generating $30 \%$ of the global concentration, an almost identical weight to that of the domestic market. In Girona, the northernmost Mediterranean province, Russian tourism also plays an important role $(16 \%)$, similar to that of the French market and close to the $21 \%$ of the domestic market. In the case of Almeria, above all, but also Cadiz, Alicante and Valencia, it is once again the domestic market that is the keydetermining factor of the situation. In the case of Barcelona, there is no particular bias towards any one market. In the other provinces, which are typically those with a comparatively lower concentration, the domestic market is generally the main provider. 
Table 8: Decomposing hotel demand monthly concentration by markets (detailed), 2012

\begin{tabular}{|l|ccccccccc|}
\hline & Dom & Ger & UK & Fra & Ita & Rus & Net & Bel & Rest \\
\hline Balearic Islands & 0,052 & 0,334 & 0,334 & 0,031 & 0,056 & 0,020 & 0,022 & 0,013 & 0,138 \\
Tarragona & 0,299 & 0,014 & 0,189 & 0,070 & 0,004 & 0,300 & 0,026 & 0,026 & 0,072 \\
Girona & 0,206 & 0,107 & 0,061 & 0,165 & 0,036 & 0,164 & 0,037 & 0,074 & 0,150 \\
Almeria & 0,829 & 0,000 & 0,035 & 0,011 & 0,006 & 0,007 & 0,009 & 0,024 & 0,079 \\
Cadiz & 0,632 & 0,231 & 0,016 & 0,017 & 0,016 & 0,003 & 0,014 & 0,016 & 0,055 \\
Málaga & 0,390 & 0,054 & 0,217 & 0,071 & 0,022 & 0,025 & 0,041 & 0,022 & 0,159 \\
Barcelona & 0,080 & 0,108 & 0,114 & 0,079 & 0,038 & 0,135 & 0,082 & 0,035 & 0,330 \\
Alicante/Alacant & 0,608 & 0,010 & 0,177 & 0,032 & 0,015 & 0,022 & 0,004 & 0,004 & 0,128 \\
Valencia/València & 0,640 & 0,009 & 0,034 & 0,058 & 0,088 & 0,011 & 0,026 & 0,010 & 0,125 \\
Seville & 0,282 & 0,074 & 0,073 & 0,149 & 0,062 & 0,004 & 0,043 & 0,020 & 0,293 \\
Granada & 0,425 & 0,127 & 0,030 & 0,144 & 0,065 & 0,006 & 0,045 & 0,028 & 0,130 \\
Palmas, Las & 0,389 & 0,200 & 0,193 & 0,044 & 0,041 & 0,000 & 0,067 & 0,030 & 0,037 \\
Madrid & 0,246 & 0,061 & 0,053 & 0,042 & 0,017 & 0,022 & 0,023 & 0,013 & 0,524 \\
Santa Cruz Tenerife & $\mathbf{0 , 1 8 6}$ & $\mathbf{0 , 2 1 9}$ & $\mathbf{0 , 0 9 6}$ & $\mathbf{0 , 0 1 9}$ & $\mathbf{0 , 0 8 9}$ & 0,016 & 0,050 & 0,037 & 0,288 \\
\hline SPAIN & $\mathbf{0 , 3 0 3}$ & $\mathbf{0 , 1 6 7}$ & $\mathbf{0 , 2 0 6}$ & $\mathbf{0 , 0 5 5}$ & $\mathbf{0 , 0 3 9}$ & $\mathbf{0 , 0 6 0}$ & $\mathbf{0 , 0 2 9}$ & $\mathbf{0 , 0 2 0}$ & $\mathbf{0 , 1 2 2}$ \\
\hline
\end{tabular}

Note: Dom is domestic demand; Ger is Germany. Fra is France; Ita is Italy; Rus is Russia; Net is Netherlands; Bel is Belgium; Rest is rest of markets

Source: Derived by present authors from Hotel Occupancy Survey (INE) data.

\section{Concluding Remarks}

As Koenig-Lewis and Bischoff (2005) demonstrated in an interesting survey on research into seasonality, the aspects relating to its measurement represent an area of particular interest. In this respect, the scant attention paid to this area by the literature is fairly surprising, particularly the lack of interest shown in adapting the instruments for measuring inequality to analyse tourist seasonality.

In this respect, this work highlights two basic issues of interest in the methodological field.

Firstly, there are different measures for approximating the level of seasonal concentration of tourist activity, including, but not only, the Gini coefficient. The important point is that every index makes a different weighting of the changes that occur in the different units of time used (e.g. months). In particular, the Gini coefficient is very sensitive to the changes that take place in the months with demand close to the average. Thus researchers have no reason to share this 
benign behaviour. In this respect, researchers might prefer other behaviour or, perhaps even better manage a set of indices to obtain a more comprehensive overview of their measurement. This paper proposes the use, apart from the Gini coefficient, of the Theil Index (which is more sensitive to changes in the months with lower demand) and the Coefficient of Variation (CV), which is neutral.

Secondly, in this measurement context, it is interesting to use decomposition techniques by factors. In this respect, two approaches have been taken: decomposition by groups and decomposition by additive sources. The former involves observing the role of groups of months, or seasons, in explaining the global concentration. The latter makes an evaluation of the role of additive sources (for example, source markets) in generating the annual concentration. With regard to group decomposition, of the three indices used the best one in methodological terms is the Theil Index. The Gini coefficient can be decomposed but only roughly, and the CV poses problems apart from not being perfectly decomposable (the sum of the group components does not give a total). With regard to additive decomposition, things are more complex. Whatever the case, the natural decomposition variance rule would also apply to $\mathrm{CV}$ and in certain eventualities it would even be a single rule irrespective of the index.

Given the above methodological points, this paper has made an empirical study of the main Spanish tourist provinces in the period 1999-2012, which should be sufficient for observing significant variations in seasonal concentration, given its limited variability in the short term. Hotel nights have been used as an indicator of tourist activity along with the abovementioned indicators and methods. In this respect, some of the main results obtained are as follows:

Firstly, the global context, across the whole country, is one of growth in seasonality, especially since 2007. In this respect, the growth of Spain as an essentially international destination has occurred without any significant correction of the seasonal concentration. This result is irrespective of the index and the time base used (i.e. monthly, four-monthly or by season). This result 
casts doubt on the sustainability of growth and is important for prioritizing corrective policies.

Secondly, although in a significant part the provincial rankings remain the same when we compare the different concentration measures (Gini, Theil and CV), there are, however, differences in some cases. Nevertheless, the concentration is typically led by the Balearic Islands and two Catalan provinces (Girona and Tarragona). On the other side of the coin are the Canary Island provinces and Madrid. Factors relating to the tourism product itself and seasonal climate variations would be behind these behavioural extremes.

Thirdly, the comparison of results in terms of the time base under consideration does not typically throw up many substantial changes but also we can find, in the detail, some divergences in some provinces.

Fourthly, the choice of index measuring seasonality at the provincial level typically does not produce significantly different results, except perhaps for the analysis on a periodic base $(5+4+3)$, where the Gini behaves differently than the others in many provinces.

Fifthly, the decomposition of the concentration by monthly groupings produced a high general explanatory capacity, especially with regard to the 5+4+3 division and the provinces with higher concentrations (typically sun-sand-beach territories). So, in these cases, it seems that these seasons can be used as references for policy monitoring and evaluation.

Fifthly, the decomposition of the monthly concentration by additive factors (by major markets) typically indicates the foreign component weighting in the level and evolution. This increase in weighting is due to both the individual share of demand and the increase in its own monthly concentration.

Finally, meanwhile, although typically the direct effect dominates the relative contribution of the major markets to the global concentration, the interrelation factor is positive, which demonstrates that the two main markets - domestic and international-strengthen each other in the explanation of concentration, without, for example, any generally significant evidence of the domestic market offsetting the foreign one up to now. In fact, the seasonality of the domestic market is even higher than that of the international market in nearly half of the provinces evaluated, and this would also grow almost half of them. 
Therefore in terms of policy (and academic) implications, these results throw some basic points:

First of all, the recent quite global unbalanced evolution, especially in the last few years, underlines the need to intensify efforts - whether this is in terms of products, markets or prices - to attenuate this seasonality.

Second, these efforts should be primarily concentrated on the markets that make the biggest contribution. In this respect, on a global level there is a need to take action, especially in international markets, and detail the strategies for each region in terms of the weighting of each of them.

Third, overall, it does not appear that the national component compensated much for the increased seasonality characteristic of the international market. In fact, seasonality in the domestic market is particularly high in many provinces, even higher than the international market. In any case, given the potential for reducing the seasonality of this market (by proximity and degree of knowledge, for example) it would seem reasonable that specific measures should be applied, especially in provinces with high weight and high seasonality in this market. It must be noted that, if this differential seasonality of domestic market is not countering an automatic policy of increasing the weight of the domestic market, it may even be counterproductive in terms of seasonality for these provinces.

Finally, although many of the results do not change when using different concentration indices, the evidence that, in some cases, discrepancies appear implies that one should move cautiously in drawing general conclusions based on a single index. An obsessive use of the Gini coefficient, on its own, is inadvisable. 


\section{References}

Allock, J. (1994). Seasonality. In S.F. Witt \& L. Motuinjo (Eds), Tourism Marketing and Management Handbook (pp. 86-92). New York: Prentice Hall. Baron, R.V. (1975). Seasonality in Tourism-A Guide to the Analysis of Seasonality and Trends for Policy Making. Technical Series, 2, Economist Intelligence Unit, London

Baum, T. (1999). Seasonality in Tourism: understanding the challengesintroduction. Tourism Economics, 5 (1), 5-8.

Butler, R. (1994). Seasonality in Tourism: issues and problems. In A. Seaton (Ed.) Tourism, The State of the Art (pp. 332-340), Chichester: Wiley.

Capó, J., Riera, A. \& Rosello, J. (2007). Accommodation determinants of seasonal patterns. Annals of Tourism Research, 34, 422-436.

Chakravorty, S.R. (1990). Ethical Social Index Numbers, Berlin: Springer Verlag,.

Cowell, F. (1995). Measuring Inequality, (2nd ed.). New York: Prentice Hall.

Cuccia, T. \& Rizzo, I. (2011). Tourism seasonality in cultural destinations. Empirical evidence from Sicily, Tourism Management, 32, 589-595.

Duro, J.A. (2012), On the automatic application of inequality indexes in the analysis of international distribution of environmental indicators. Ecological Economics, 76, 1-7.

Fernandez-Morales, A. (2003). Decomposing seasonal concentration. Annals of Tourism Research, 30 (4), 942-956.

Fernandez-Morales, A. \& Mayorga-Toledano, M.C. (2008). Seasonal concentration of the hotel demand in Costa del Sol: A decomposition by domesticities. Tourism Management, 29, 940-949.

Gini, C. (1912). Variabilità e mutabilità, contributo allo studio delle distribución e relazioni statistiche. Studi Economico-Giuridici dell' University di Cagliari. 3, part 2, 1-158.

Goerlich, F. (1998). Desigualdad, Diversidad y Convergencia: (algunos) instrumentos de medida. monografía 1998-01, IVIE.

Koenig-Lewis, N. \& Bischoff, E. (2005). Seasonality research: the state of the art. International Journal of Tourism Research, 7, 201-219. 
Krakover, S. (2000). Partitioning seasonal employment in the hospitality industry. Tourism Management, 2, 461-471.

Lerman, R. \& Yitzaki, S.(1985). Income inequality effects by income. The Review of Economic and Statistics, 67, 151-156.

López, J.M. \& López, L.M. (2006). La concentración estacional en las regiones españolas desde una perspectiva de la oferta turística. Revista de Estudios Regionales, 77, 77-104.

Lundtorp, S. (2001). Measuring tourism seasonality. In T. Baum and S. Lundtorp (Eds.). Seasonality in tourism (pp. 23-50). Oxford: Pergamon.

Manning, R.E. \& Powers, L.A. (1984). Peak and off-peak use: redistributing the outdoor recreation/tourism load. Journal of Travel Research, 23 (2), 25-31.

Martin, J.M., Jiménez, J. \& Molina, V. (2014). Impacts of seasonality on environmental sustainability in the tourism sector based on destination type: an application to Spain's Andalusia region. Tourism Economics, 20(1), 123-142.

Rosello, J.A., Riera, A. \& Sanso, A. (2004). The economic determinants of Seasonal patterns. Annals of Tourism Research, 31, 697-711.

Shorrocks, A. F. (1980). The class of additively decomposable inequality measures. Econometrica, 48(3), pp. 613-625.

Shorrocks, A. F. (1982). Inequality decomposition by factor components. Econometrica, 50(1), pp. 193-211.

Shorrocks, A. F. (1984). Inequality decomposition by population subgroups. Econometrica, 52(6), pp. 1369-1385.

Theil, H. (1967). Economics and Information Theory. Amsterdam: North Holland.

Wanhill, S. (1980). Tackling seasonality: A technical note. International Journal of Tourism Management, 1(4), 84-98.

Zaiger, D. (1983). Inequalities for the Gini coefficient of composite populations. Journal of Mathematical Economics, 12. 